\title{
Professional Learning in the Midst of Teaching Computer Science
}

\author{
Aleata Hubbard \\ WestEd \\ Redwood City, California \\ ahubbar@wested.org
}

\author{
Katie D'Silva \\ WestEd \\ Redwood City, California \\ kdsilva@wested.org
}

\begin{abstract}
The recent groundswell of interest in computer science education across many countries has created a pressing need for computing teachers at the secondary level. To satisfy this demand, some educational systems are drawing from their pool of in-service teachers trained in other disciplines. While these transitioning teachers can learn about computing pedagogy and subject matter at professional learning workshops, daily teaching experiences will also be a source of their learning. We studied a co-teaching program where instructional responsibilities were distributed between teachers and volunteers from the tech industry to explore how specific teaching practices supported teacher learning, with a focus on pedagogical content knowledge (PCK). Through qualitative analysis of questionnaire and interview data gathered from three teachers during one school year, we identified the practices they engaged in and how their learning related to the enactment of those practices. Our results highlight several factors that influenced the ways in which teaching practices provided participants with opportunities to learn PCK: (a) active participation of students and volunteers; (b) teacher's level of content knowledge; (c) interdependent practices; and (d) immediacy of the classroom environment.
\end{abstract}

\section{CCS CONCEPTS}

- Social and professional topics $\rightarrow \mathrm{K}-12$ education;

\section{KEYWORDS}

Pedagogical content knowledge, high school teachers, teaching practice

\section{ACM Reference Format:}

Aleata Hubbard and Katie D'Silva. 2018. Professional Learning in the Midst of Teaching Computer Science. In ICER '18: 2018 International Computing Education Research Conference, August 13-15, 2018, Espoo, Finland. ACM, New York, NY, USA, 9 pages. https://doi.org/10.1145/3230977.3230983

\section{INTRODUCTION}

In the past several years, many countries have started initiatives to expand computer science (CS) education at the primary and secondary level [25]. Across the U.S., where we work, efforts such

Permission to make digital or hard copies of all or part of this work for personal or classroom use is granted without fee provided that copies are not made or distributed for profit or commercial advantage and that copies bear this notice and the full citation on the first page. Copyrights for components of this work owned by others than the author(s) must be honored. Abstracting with credit is permitted. To copy otherwise, or republish, to post on servers or to redistribute to lists, requires prior specific permission and/or a fee. Request permissions from permissions@acm.org.

ICER '18, August 13-15, 2018, Espoo, Finland

(C) 2018 Copyright held by the owner/author(s). Publication rights licensed to ACM. ACM ISBN 978-1-4503-5628-2/18/08 . \$ \$15.00

https://doi.org/10.1145/3230977.3230983 as CS10K [12] and CS for All [23] are providing more students with access to CS learning opportunities. Some of the largest K-12 districts in the country serving hundreds of thousands of students are implementing computing curricula across their schools [39, 43]. A major requisite to the sustainability of these plans is a sufficient pool of teachers versed in both CS content and pedagogy.

However, there is a shortage of CS teachers at the secondary level in the U.S. One reason for this scarce supply is a limited number of pre-service training programs available to prepare aspiring teachers. Given the paucity of pre-service opportunities, alternative pathways for in-service educators exist through teaching endorsements and accreditation [30]. Yet, manifold pathways make it possible for teachers to enter CS classrooms without adequate preparation. The CS education community has recognized a need to support these transitioning teachers in developing the knowledge and skills needed to effectively teach and increase participation in CS [15].

While professional learning (PL) programs exist for these teachers, many are of insufficient duration and do not focus clearly on teacher knowledge specific to computer science [35] . Furthermore, when participants enter PL experiences with differing backgrounds, amounts of teaching experience, and prior knowledge, it is challenging for teacher educators to create effective learning opportunities [47]. Understanding how in-service teachers incorporate experiences from PL into their practice can (a) provide a realistic portrait of CS teacher knowledge development and (b) inform the design of future, possibly differentiated, PL opportunities. With these goals in mind, we report on our efforts to investigate the teacher learning of educators transitioning into CS through a PL program embedded into their daily teaching.

\section{TEACHER KNOWLEDGE AND LEARNING}

The craft of teaching draws upon many types of knowledge such as knowledge of subject matter, knowledge of individual students, knowledge of how people learn, and knowledge of curricula [13]. In our work, we focus on pedagogical content knowledge (PCK), a construct introduced by Shulman [45] to characterize the knowledge needed for teaching a particular subject. Shulman originally described PCK as a subset of content knowledge that includes knowledge of student understanding and knowledge of teaching practices to support learning. Familiarity with common errors and evaluating the advantages and disadvantages of representations used for instruction are examples of PCK [5]. This framework has been extremely influential in the study of teacher learning, particularly in mathematics [14] and science [42].

Research on PCK, both within and outside of CS, has produced some consistent findings. First, PCK is subject specific and strongly 
correlated to content knowledge [8]. In a study of experienced computing teachers learning to teach a new programming paradigm, Liberman et al. [32] explored the connection between PCK and content knowledge. They found teachers entered a state of regressed expertise where they displayed elements of both novice teaching and expert teaching. Second, PCK develops incrementally with a focus first on learners and then later on teaching practices [42] Buchholz et al. [10] provided anecdotal evidence that pre-service CS teachers progress through stages of complexity in their PCK when developing teaching modules. Similarly, Lapidot's [31] field study with fifteen in-service and pre-service teachers resulted in a model explaining stages of CS teacher learning which progress from a focus on content knowledge, to creating instructional examples, to supporting student understanding, to improving their practice. And third, various personal and contextual factors influence PCK development [2, 40]. Baxter [6] and Griffin, Pirmann, and Gray's [21] case studies comparing experienced CS teachers demonstrated how PCK can vary across teachers with similar levels of expertise and be enacted differently in their classrooms.

Related to PCK is professional learning, or the various activities teachers engage in to improve their knowledge and practice. These activities range from informal chats with colleagues to formal workshops facilitated by teacher educators. Changes in teacher learning take time and vary across individuals [9]. Research points to the value of linking professional learning to authentic practice because it allows for active learning related to the contexts within which teachers work $[3,19]$. Some teacher education researchers are beginning to focus less on the components of PCK and more on describing the core practices of teaching that enable educators to apply their knowledge in classrooms [18, 34]. Some of these practices include leading a discussion, assessing student knowledge, presenting ideas, finding examples to make a specific point, connecting a topic to topics taught in prior or future years, appraising content on instructional materials, modifying tasks to be easier or harder, and selecting representations $[5,26]$. However, scholars are still undecided about what teaching knowledge is needed for effectively using core practices [4].

In our work, we are studying a PL program that connects to authentic practice through co-teaching with technology professionals. Such collaborations tend to involve joint or distributed effort around planning and teaching [22]. When situated within classrooms, the learning opportunities that these partnerships offer will depend on the contexts within which they occur and on the participating teachers and external partners. Our goal is to understand how such PL embedded within daily teaching can support the learning of transitioning CS teachers, with a focus on PCK. Specifically, we ask: (a) what instructional practices do teachers undertake when planning and enacting their lessons within a co-teaching partnership? and (b) how does teacher learning relate to the implementation of these instructional practices?

\section{METHOD}

\subsection{Study Context and Participants}

Our project explores PCK and teacher learning within a multi-year, on-the-job training program that pairs teachers with volunteers from the tech industry to offer CS courses in secondary schools across the U.S. At the start of the partnership, volunteers lead CS classes while teachers learn course content. Over time, responsibilities shift from volunteers to teachers, with teachers leading their courses independently after two years. The program offers two courses. The semester-long Introduction to Computer Science Principles course (Intro) introduces some of the big ideas of computing, discusses the history and future of the field, and teaches students programming with the block language Snap!. Many teachers extended Intro into a year-long course by teaching additional programming languages or curricula the second semester. The yearlong Advanced Placement Computer Science A course (AP CS A) introduces students to object-oriented programming and the Java programming language. Advanced Placement is a program in the U.S. run by the non-profit College Board that provides college level courses for secondary students. We studied three teachers in the second year of the program: Ms. Robinson, Mr. Miller, and Mr. Perez (all pseudonyms).

Ms. Robinson taught one section of the AP CS A course with four volunteers. At the time of the study, she had 11 years of teaching experience. She also taught geometry and an introductory computing course (not through the PL program). Ms. Robinson's professional experiences prior to teaching involved multiple roles in the tech industry including web designer, quality assurance engineer, and software engineer. However, her tech career occurred 15 years ago. While she remembered some computing concepts, she saw herself as a "novice teacher in CS field" who relied on volunteers and experienced students to help her with the course content.

Mr. Miller taught two sections of the Intro course. He taught the first section collaboratively with two volunteers and the second section independently. During the second semester of the course, his team introduced students to HTML and CSS. He had 38 years of teaching experience and he also taught algebra. Mr. Miller had prior programming experience in the 1970s. While he felt confident in his conceptual understanding of computing, he felt his knowledge needed updating.

Mr. Perez taught one section of the Intro course with three volunteers. To extend his course to a full year, he included components of Computer Science Principles (AP CSP), a new computing course offered by the College Board. In the year prior to this study, he taught one section of the AP CS A course. He had two years of teaching experience and he also taught algebra. Mr. Perez felt very comfortable with CS content. In secondary school and college, he took computing courses in BASIC, C++, Java, Racket, Prolog, and Fortran. Mr. Perez had experience tutoring college students in computer science.

Although we present data gathered from three participants, our goal is not to compare the quality or preparedness of the teachers. Instead, we are providing an array of possible ways transitioning teachers might engage in and learn from their instructional practices.

\subsection{Data Collection and Analysis}

This study spanned an entire school year, beginning in September 2015 and ending in June 2016. Data collection centered around visits, or a set of activities related to an observed classroom lesson. Visits focused on lessons so that participants could draw on their 
recent experiences when completing questionnaires and interviews. We conducted five or six visits with each teacher.

Each visit began with a questionnaire teachers completed before the observation. This questionnaire asked ten open-ended items and one close-ended item about teaching knowledge for the upcoming lesson. Most items were drawn from the CoRe [33], a set of prompts to guide groups of teachers in discussing PCK related to a specific topic.

To capture immediate impressions of their teaching, participants were interviewed about their lessons directly after the observation. Probing questions focused on how the lesson supported students, unexpected occurrences, and ideas for revising the lesson. Questions were adapted from protocols used to interview mathematics teachers about the development of their technology PCK [38]. We included three questions focused on the quality of the co-teaching experience, the roles assumed by teachers and volunteers, and the effectiveness of co-teaching in preparing teachers to lead the lesson independently. We also used this interview as an opportunity to clarify any ambiguous or terse comments provided on the prelesson questionnaire. Lastly, during half the visits, participants also completed think-aloud interviews where they reviewed either a set of assessment items or a set of student responses to a programming problem (see [24]). While these think-aloud interviews focused primarily on eliciting their PCK for specific computing topics, each teacher made one or two comments related to their teaching practices that are also included in this analysis.

Within two days of the observation, after teachers had time to reflect more on their lessons, they completed a post-lesson questionnaire. The first half of this questionnaire focused on the methods and instructional resources used to prepare and deliver their lesson. Most items were drawn from the Horizon Inside the Classroom Interview Protocol [46] and all items required written responses.

We analyzed interview responses and open-ended questionnaire items to identify instances where participants discussed PCK, content knowledge, instructional practices, or their own growth as a teacher. Our unit of analysis was the entire response provided to a prompt listed on our interview protocol or to a questionnaire item. In dividing the data using this approach, units from interviews might contain multiple questions if the interviewer asked clarifying questions. Our coding scheme, which draws heavily on the work of Shulman [45] and Ball, Thames, and Phelps [5], contains three main categories: CS teaching knowledge (see Table 1), instructional practices (see Table 2), and 'other'. This last category was used to capture instances where teachers either talked about their own development or mentioned ideas outside the other categories.

To conduct an exploratory analysis into the relationship between practices and PCK, we used Ball and Cohen's [3] approach to professional learning as an interpretive guide. Their model highlights how many teaching tasks can support an examination of practice because "in the course of these tasks, teachers may puzzle, weigh alternatives, draw on what they know or can access as resources for judgments and decisions." We examined how different teaching practices discussed by participants allowed for active noticing, interpretation, and working with artifacts of practice.

The second half of the post-lesson questionnaire contained six close-ended items asking teachers to rate the degree to which they and their volunteers contributed to instructional practices related to
Table 1: Teaching Knowledge Coding Scheme

\begin{tabular}{ll}
\hline Category & Definition \\
\hline $\begin{array}{l}\text { Student understanding and } \\
\text { difficulties }\end{array}$ & $\begin{array}{l}\text { Knowledge of student ideas and mis- } \\
\text { conceptions about CS }\end{array}$ \\
\hline $\begin{array}{l}\text { Student interest and motiva- } \\
\text { tion }\end{array}$ & $\begin{array}{l}\text { Knowledge of student interest and } \\
\text { motivation related to CS }\end{array}$ \\
\hline $\begin{array}{l}\text { Representations and teach- } \\
\text { ing methods }\end{array}$ & $\begin{array}{l}\text { Knowledge of how topics are repre- } \\
\text { sented and how topics can be pre- } \\
\text { sented to learners }\end{array}$ \\
\hline Timing, pacing, sequencing & $\begin{array}{l}\text { Knowledge of how topics should be } \\
\text { organized to support learners }\end{array}$ \\
\hline
\end{tabular}

Table 2: Instructional Practices Coding Scheme

\begin{tabular}{ll}
\hline Category & Definition \\
\hline Planning Lessons & $\begin{array}{l}\text { Search for and evaluate instruc- } \\
\text { tional materials }\end{array}$ \\
\hline Find materials & Create instructional materials \\
\hline Create materials & $\begin{array}{l}\text { Modify instructional materials cre- } \\
\text { ated by others }\end{array}$ \\
\hline Review materials & $\begin{array}{l}\text { Look over existing instructional ma- } \\
\text { terials }\end{array}$ \\
\hline Practice materials & $\begin{array}{l}\text { Complete tasks that will be assigned } \\
\text { to students }\end{array}$ \\
\hline Organize lesson & $\begin{array}{l}\text { Decide on the timing, pacing, se- } \\
\text { quencing of lessons; Create student } \\
\text { groups for team work }\end{array}$ \\
\hline Enacting Lessons & Provide help to students \\
\hline Assist students & $\begin{array}{l}\text { Assess students, assign grades, re- } \\
\text { view student progress }\end{array}$ \\
\hline Evaluate learning & $\begin{array}{l}\text { Present information through whole } \\
\text { class instruction }\end{array}$ \\
\hline Present ideas &
\end{tabular}

lesson preparation (i.e., developing lessons, creating assignments), instructional delivery (i.e., delivering lessons, managing the classroom), and evaluation of learning (i.e., assisting students, grading student work). These six practices were drawn from materials created by the PL program to describe the roles of teachers and volunteers. Option choices were: mostly teacher, both volunteers and teacher, mostly volunteer, and no one. We converted these levels into numeric values and averaged engagement in instructional practices over the school year. Since we were most interested in the degree to which teachers engaged in instructional practices, we collapsed the levels of "no one" and "mostly volunteers" to a value of 0 , assigned "both volunteers and teachers" a value of 1 , and assigned "mostly teacher" a value of 2 . 
3.2.1 Trustworthiness of Data. Both authors, who were also involved in data collection, coded the interview and open-ended questionnaire data. We went through three steps to establish interrater reliability: training, agreement, and reliability. In the training phase, the first author introduced the coding scheme to the second author, providing the second author with examples to illustrate each coding category. In the agreement phase, we reviewed a subset of data files together and discussed how we would code them, resolved discrepancies in our decisions, and made decisions on how to handle similar cases in the future. This form of negotiated agreement is useful when conducting exploratory work and can help to increase reliability [11]. In the reliability phase, we separately coded a subset of the data and compared our coding choices using Krippendorff's alpha reliability measure [28, 29]. Most categories passed Krippendorff's suggested threshold value of .67, one category fell just below the threshold at $\alpha=.66$ (i.e., knowledge of student interest and motivation), and one category never occurred in the reliability set (i.e., review materials).

Since researchers have cautioned against relying solely on teacher self-report data [41], we compared teachers' self-reported data about the frequency of their instructional practices to observation data gathered by the research team. While the data showed that participants' self-reported data aligned mostly with observation data, there was one discrepancy. Mr. Miller sometimes disagreed with observers on whether he or his volunteers assisted students more in class. We believe Mr. Miller was distinguishing the ways in which he and volunteers were providing support to students (e.g., formal code reviews versus answering individual questions) and that he may have concentrated on a subset of these methods of support when reporting on the distribution of this responsibility.

\section{RESULTS}

\subsection{Instructional Practices Enacted}

4.1.1 Distribution of Practices. In the PL program we studied, teams distributed responsibilities across teachers and volunteers. While the PL program offered guidance on the distribution of responsibilities, teams divided their daily teaching tasks differently depending on factors such as teacher readiness and volunteer availability. We first identified the degree to which teachers enacted the six practices highlighted in their PL program materials (see Figures 1-3).

All teachers reported undertaking each of the six practices in their CS classes to some degree. The responsibility of managing the classroom (e.g., taking attendance, making sure students stay on task) fell mostly to the teachers. However, different profiles appeared in our three participants when looking at the other five practices. Ms. Robinson had more opportunities to focus on analyzing student work than on other responsibilities through assisting students in class and grading their work. Mr. Miller had a high level of involvement in multiple responsibilities, but he was noticeably less involved in assisting students and creating assignments. Mr. Perez assumed most of the responsibilities in his class and his volunteers provided support mostly through grading student work.

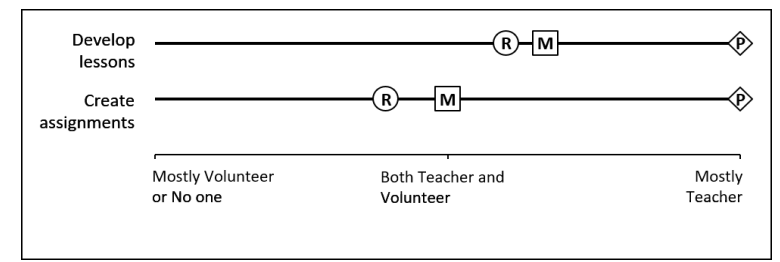

Figure 1: Self-reported distribution of lesson preparation tasks across school year. Letters indicate the first letter of each teachers name.

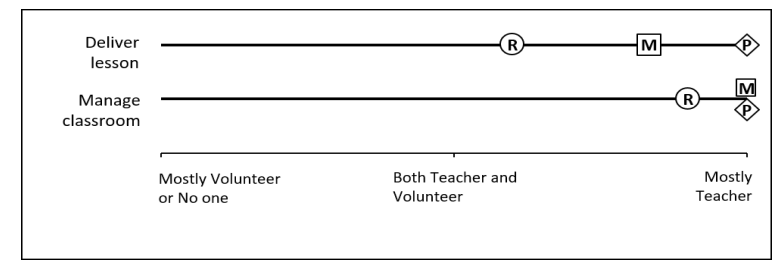

Figure 2: Self-reported distribution of instructional delivery tasks across school year.

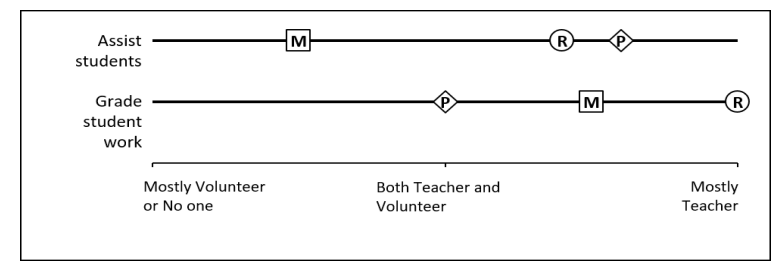

Figure 3: Self-reported distribution of evaluation of learning tasks across school year.

4.1.2 Discussion of Practices. To gain additional insight into the practices participants enacted, we reviewed open-ended questionnaire responses and interviews to identify instances where teachers described instructional practices included in our literature-derived coding scheme. Table 3 shows the number of units in our data set where teachers discussed these practices. For example, Ms. Robinson discussed instructional practices in 28 of her units; 10 units focused on assisting students. Note that units could receive multiple codes, allowing for totals of subcategories to exceed the total of their parent category.

Despite responding to the same questionnaires and interviews, we saw differences in the specific practices each teacher discussed. Ms. Robinson's comments focused more on practices related to enacting her lessons than to practices related to planning lessons. She did, however, discuss one lesson planning practice (i.e., reviewing materials) multiple times. Also, there were two practices she never discussed with us: finding materials and modifying materials. This may be explained by her reliance on volunteers to lead the class and by her teaching team following the PL curriculum closely. As she commented during our first visit to her classroom: "We are following along the [PL] lesson plan, a guide. So we are using the work - pretty much following it very closely. Sometimes we don't, but most of the time we do." 
Table 3: Number of Units Focused on Instructional Practices

\begin{tabular}{|c|c|c|c|}
\hline Category & Robinson & Miller & Perez \\
\hline Planning Lessons & 11 & 23 & 21 \\
\hline Find materials & 0 & 2 & 5 \\
\hline Create materials & 1 & 3 & 6 \\
\hline Modify materials & 0 & 1 & 3 \\
\hline Review materials & 5 & 6 & 1 \\
\hline Practice materials & 3 & 2 & 6 \\
\hline Organize lesson & 3 & 9 & 8 \\
\hline Enacting Lessons & 20 & 35 & 11 \\
\hline Assist students & 10 & 9 & 6 \\
\hline Evaluate learning & 7 & 14 & 3 \\
\hline Present ideas & 4 & 20 & 4 \\
\hline Total Units (n) & 28 & 51 & 29 \\
\hline
\end{tabular}

Similar to Ms. Robinson, Mr. Miller's comments focused more on practices related to enacting lessons than on practices related to planning lessons. He also discussed one lesson planning activity (i.e., organizing lessons) several times. He talked most often about presenting ideas. This may be explained by the setup of his partnership where he co-taught first period and taught independently second period. He sometimes shared with us comparisons of the two lessons or ways he revised his second period lesson based on reactions to the first period lesson. For example, he once said, "I like that [my volunteer] put in his repeat until [block], because that was a working game - I did it a little differently in second period, I made it a working game."

Lastly, Mr. Perez' discussion of practices was more evenly distributed across all nine practices. This might be explained by his assuming more of the responsibility in his course than his volunteers, creating the need for him to attend to more of the instructional practices. Based on our first conversation with Mr. Perez, this approach aligned with his goals for the school year:

So, it being my second year of [the PL program], I have been interpreting that as I should be taking the lead more. And having gone through the training over the summer, I felt like I knew the curriculum a lot better than [the volunteers] did, and so I didn't want to trust my kids to other people.

\subsection{Learning through Instructional Practices}

In the second phase of our analysis, we reviewed participant data to identify ways in which their instructional practices provided opportunities for teacher learning and factors that influenced these learning opportunities. Since teacher learning is a complex process influenced by personal and contextual factors [2] that might lead to differences in how instructional practices influence the learning process, we present the results for each participant separately.

4.2.1 Ms. Robinson. During this study, Ms. Robinson assumed a mostly supportive role in her course while her volunteers led many of the lessons. As we saw from her questionnaire and interview data, she enacted and talked most about assisting students and evaluating student learning. It appears these practices supported her own learning by providing multiple artifacts of practice (i.e., student work to the same problems) that allowed her to identify common approaches employed by her students as well as their areas of difficulties. For example, she once discussed how grading a test revealed a common misconception amongst her students of how nested loops execute:

Well based on the tests that I was correcting yesterday kids were having trouble with for loops. That was the highest commonly missed problem...a nested for loop...In fact, that is one of the things I want to go over with the [volunteers]. It is just understanding that when you start with the first for loop, that is related to the row. (Ms. Robinson, Sept. 25, 2015)

Her ability to enact these practices given her novice level understanding of the course content was supported by reviewing and practicing materials. During these lesson preparation practices, she often reviewed completed solutions from either her volunteers or the PL curriculum. Reviewing completed solutions allowed her to identify salient aspects of the lesson content that guided her assessment of student work. For example, she once described how a completed programming solution helped her decide how to check the methods students wrote to shuffle values:

I had the solution, so I can compare, like 'Okay, well this is what you are supposed to do.' I mean, I used it as my guide...And I am glad I did look at the code beforehand because I did notice that they had to use math.random and that gives it more of a random mix of shuffle. So if they got at least half of activity three which included the random, I would just move on. (Ms. Robinson, March 28, 2016)

Some of the practices Ms. Robinson discussed did not reveal evidence of how they supported her computing PCK. For example, when discussing how she organized her lessons, she talked about sticking to timelines. Or, when discussing how she presented ideas, Ms. Robinson would often indicate that her presentation lasted longer than expected. In addition to classroom responsibilities, Ms. Robinson was heavily engaged in the expansion of CS education in her region. She acknowledged that attending to advocacy reduced the amount of time she had to focus on learning course content:

So I am like marketing, advertising, promoting, teaching, and getting people to help because I don't know all of this computer science...And so I am pretty spread thin...I am just trying to get the word out. That is why I don't have that much time to you know even sometimes do the curriculum. But I am taking advantage of the great volunteers that I have, because they can deliver. (Ms. Robinson, December 9, 2015)

While she had little time to learn content, advocacy work seemed to keep Ms. Robinson motivated in her teaching assignment. Other factors, such as motivation, may be as important to developing and sustaining effective teachers as PCK.

4.2.2 Mr. Miller. During this study, Mr. Miller and his volunteers were in a collaborative stage of their co-teaching partnership where all members contributed to the planning and delivery of 
lessons. His data revealed how combinations of practices provided a cycle of feedback to support his learning. For example, when we visited Mr. Miller in November, his class was working on list traversals. Students had to create a list of names and then create scripts to extract subsets of the list. Mr. Miller described how he first practiced the assignment himself and then, while presenting the lesson, received feedback from a volunteer on improving his script:

I love the co-teaching because [the volunteer] even pointed out that I had this unnecessary variable in my script. Because I am never sure if I am doing this right. I love it if a programmer can sit down and say 'here is what I would have done instead.' [My solution] worked, so I knew it was somewhat right, but, yeah, there is a better way to do it. (Mr. Miller, November 20, 2015)

Closer to the end of the school year, we visited Mr. Miller during a lesson where the class reviewed a recent quiz on HTML. He described how there was a syntax error in one of the quiz items he created, an error that he only became aware of when grading student responses:

I took last year's quiz, and it was half on HTML and half on JavaScript. So I just took away all the JavaScript questions and added my own HTML and CSS questions. Thursday night as I was correcting it, I realized I made a mistake in writing the code. I forgot the semi-colon in one place. So I just made it part of the lesson, saying did anybody notice something missing. (Mr. Miller, March 28, 2016)

Grading this quiz also provided Mr. Miller with a bank of student responses from which he identified common errors and habits such as 'a lot of people didn't close the opening tag' or 'they would use upper case in one place and lower case in another', all of which helped to build his knowledge of student understanding of HTML and CSS.

There were some ways in which instructional practices did not support Mr. Miller's learning. First, his comments suggest that time and limited student engagement may have constrained his opportunities to learn. For example, he spent less time assisting individual students in class so that he could circulate to more pupils:

And there are times like that where I am walking through the class, and [the students] will say 'I don't get it, this isn't working.' And I don't always catch [the issue] right away. I feel great when I do, but sometimes it is more complex. I don't have five minutes to stand there and go, 'wait, let's see, let me think out.' So I have to say, 'you should go block by block through it and do the same sort of debugging techniques.' (Mr. Miller, October 2, 2015)

So, assisting students in real time restricted how deeply he could reflect on student work. While this may have limited Mr. Miller's opportunity to learn, it may have enhanced his students' opportunities to learn as they took on more of the debugging work. Also, throughout the school year, Mr. Miller discussed an occasional lack of participation from his students during lectures and how "nobody says anything." When students did not offer answers or pose questions, Mr. Miller had no feedback to inform his knowledge of student understanding or revisions for his lessons. Lastly, management tasks also presented a barrier for Mr. Miller's learning. Sometimes while he took attendance or passed out prizes provided by the PL program, Mr. Miller relegated more content-focused practices to volunteers:

I had a little trouble with timing. I was very happy to have the volunteers there because I tried to walk around and let them help students, and then I wanted to deal with the raffle, deal with the warmups, and the one girl who lost her password on the survey. There was another student who asked to use the printer. So all these little interruptions that I try and comply and answer to, it takes away from class time. (Mr. Miller, May 13, 2016)

4.2.3 Mr. Perez. Mr. Perez assumed most of the teaching responsibility in his class so he was involved in all the practices we examined. Much of his activity during the study focused on experimenting with the Computer Science Principles curriculum. He was "trying riskier strategies, flying blind in an attempt to gather data to inform next year." Because he was working with a new curriculum, he spent a lot of time finding and modifying materials and then creating a presentation to deliver content or rubrics to students. For example:

I found sample scripts with bugs through [Beauty and Joy of Computing] and other CS teachers and solved each problem on my own. I also organized these scripts into a presentation that had them in manageable chunks...These resources provided the scripts that guide students' thinking to most effectively practice Boolean operators, script variables, and for loops. (Mr. Perez, October 5, 2015)

Although Mr. Perez felt comfortable with computing, he felt overwhelmed by this cycle of finding, modifying, and creating materials, which left little time for him to reflect on the materials. This was notably apparent in a lesson we observed focused on nesting higher-order functions (i.e., map, keep, combine):

[I am] feeling like I am still figuring things out, in general. Not making sense of the material, but flying by the seat of my pants in terms of preparing - like, converting it from [Beauty and Joy of Computing] webpage format to working in a high school classroom format. Those things have felt like a little much. (Mr. Perez, October 27, 2015)

Despite this discomfort, and maybe to overcome it, Mr. Perez often practiced the problems he planned to give his students, which supported his initial ideas around organizing lessons. However, it was the enactment of those lessons that gave him feedback on areas where students needed more guidance and on ordering content to better support their learning:

I would also rethink how I introduce and emphasize nested [higher order functions] so that it is a more deliberate process; I might also want to emphasize composition of functions earlier in the course so that students 
are familiar with the idea before applying it to [higher order functions] (Mr. Perez, October 27, 2015)

Mr. Perez also discussed some of the typical student approaches to tasks in this lesson, such as using "a bunch of script variables to store intermediate results" instead of the higher order functions. In addition to student feedback during lessons, he also uncovered this information through assisting students in lab time where he preferred to spend more time with those struggling with content:

The closer work I was able to do with those struggling students allowed me to get a better idea of the types of ideas students might struggle with, and the types of thinking that would cause them to struggle. This will help me to plan and instruct better this year and in future years. (Mr. Perez, October 27, 2015)

To support this approach, he let his volunteers circulate around to the rest of the students and created a classroom culture where students felt comfortable asking each other for help.

\section{DISCUSSION}

A teacher's role is multifaceted and involves many responsibilities ranging from subject specific tasks (e.g., preparing instructional materials), general pedagogical activities (e.g., classroom management), and other professional obligations (e.g., coaching extracurricular teams). Teachers are often overwhelmed when confronted with all these responsibilities once they enter the classroom and find it difficult to attend to relevant events [16, 17]. At the same time, experience is a key factor in developing teaching expertise [7]. In our work with transitioning teachers, we have wondered (a) how exactly does this learning from experience happen and (b) can we offer guidance on how transitioning teachers should focus their classroom experiences to better support their development? The co-teaching arrangement we studied provided the opportunity to explore how teaching practices allowed for teacher learning within authentic classroom environments.

We first examined the instructional practices teachers enacted related to specific lessons. Questionnaire and interview data highlighted that teachers were involved in nearly all the practices we examined, but that the distribution of these practices between teachers and volunteers varied across teaching teams. In all cases, coteaching alleviated some of the workload allowing teachers to focus more on the practices of their choosing. As Mr. Miller once said, "co-teaching takes much of the pressure to 'do it right' off my shoulders."

Next we examined how the implementation of these instructional practices related to learning and opportunities for participants to develop their PCK. Enacting these practices allowed teachers to work with authentic artifacts of practice (e.g., student work), evaluate the utility of materials to support student understanding, reflect on how best to present content to students, and apply their content knowledge. While Ms. Robinson, Mr. Miller, and Mr. Perez differed in how they engaged and learned from these practices, we noticed some commonalities across the teachers' experiences.

First, the usefulness of some practices for teacher learning depended on the active participation of students and volunteers. For example, presenting information during a lecture was helpful when students provided ideas or responded to teachers' questions. Or, creating materials when one was not completely confident with the content was helpful when volunteers highlighted inaccuracies or inefficiencies in the work. In other words, instructional practices became learning moments when teachers and other classroom actors interacted. This finding aligns with sociocultural theories that view teacher learning as "distributed across all participants in professional practice (including, in this case teachers and students) and which relate to both the conceptual and the physical resources available" [27].

Second, content knowledge played a role in the way teachers learned from their practices. For example, Ms. Robinson, who was less comfortable with her course content, benefitted from reviewing completed solutions because they highlighted what she should focus on. In contrast, Mr. Perez, who felt very comfortable with computing, benefitted from completing problems himself because it sparked ideas of how to organize his lessons. Differences mediated by content knowledge were expected because prior research has demonstrated a strong correlation between content knowledge and PCK [8]. Without strong content knowledge, teachers struggle to notice and understand student thinking and to participate in useful discussions with their colleagues [20]. However, we saw evidence that reviewing solutions completed by more knowledgeable others might support PCK development in ways that practicing materials might not afford. Namely, reviewing materials can scaffold teachers' noticing of common or effective approaches. This finding aligns with the literature showing the value of worked examples to support learning [1].

Third, learning often occurred across practices. For example, Mr. Miller created materials for students, but opportunities for his learning occurred when he evaluated student work in response to those materials. Or, in the case of Mr. Perez, he often found materials related to the new Computer Science Principles curriculum to use in his class. But, opportunities for his learning occurred when he began to modify the materials. So, there might be constellations of practices to consider that provide teachers with cohesive experiences where they can notice, interpret, and work with artifacts of practice.

Fourth, enacting practices in real-time did not always allow sufficient time for teacher learning. For example, the need to circulate to all students during lab time made it challenging to spend extended periods with struggling students and learn from their difficulties. Or, the need to create or revise materials to present on a certain date sometimes restricted time to reflect on the best ordering of content to scaffold student learning. This is not entirely unexpected given the cognitive load required to process all the information and activities occurring within a classroom [17]. Furthermore, Ball and Cohen [3], whose ideas we used to analyze data in this study, caution that situating teacher learning in the classroom "confines learning to the rush of minute-to-minute practice" and "interferes with opportunities to learn." Thus, there may be some practices that would support teacher learning better if they happened outside of classroom teaching, at a time where teachers can be more reflective and are not attending to the immediacy of the classroom.

Lastly, not all practices provided opportunities for learning related to PCK, nor should we expect them to. Successful teaching 
involves more than just content-focused activities. For example, Ms. Robinsons' advocacy work outside the classroom seemed to serve as a motivator for her new role as a CS teacher and a vehicle for connecting with peers. Belonging to a professional community can help teachers overcome the isolation that is common amongst many CS teachers [37]. The data highlighted, however, that reducing some practices might service teacher learning more. For example, aspects of managing the classroom (e.g., distributing materials) could be offloaded to volunteers so that teachers focus on PCK-building practices.

At this point in our work, we have noticed that (a) instructional practices might vary in the opportunities they provide for developing PCK expertise and (b) the usefulness of responsibilities might vary based on a teacher's content knowledge. While still exploratory, these results may have heuristic value for thinking more about the relationship between instructional practices and PCK development. A few limitations in our work are worth noting. Given the semi-structured format of the interviews and the focus on individual lessons, caution should be exercised in interpreting the data. First, the total number of units where teachers discussed instructional practices were few, accounting for less than $25 \%$ of each teacher's total units. This study was situated within a larger project focused primarily on PCK, so the majority of participants' units addressed teaching knowledge. Second, study visits focused on individual lessons and not entire units; it is possible that teachers performed other practices outside of the study visits that were not discussed during interviews. Designing more systematic ways of eliciting the ways instructional practices support teaching learning is an obvious next step for this work.

\section{CONCLUSION}

To expand CS education in primary and secondary schools, many experienced teachers are facing a discipline they themselves have not learned formally. These teachers need to be supported so they develop not only the declarative PCK needed in CS classrooms but also the procedural know-how to use this PCK effectively. This concern, however, is not solely for transitioning teachers. Even experienced CS teachers will need to update their teaching knowledge base to incorporate new material, programming languages, or paradigms into their courses (see [32] for an example). We urge more scholars to focus on the enacted element of PCK so that we can better understand how teachers new to CS or experienced CS educators teaching new topics improve upon their craft through their classroom experiences. Here we end with a few questions to further research in this area.

How can instructional practices be scaffolded to better support teacher learning? We saw earlier that Ms. Robinson benefitted from reviewing materials completed by her volunteers because it drew her attention to salient aspects of the solution. There may be ways in which materials can be designed to encourage noticing of important features. Morrison, Margulieux, Ericson, and Guzdial [36] provide such an example with the use of subgoal labeling of Parsons problems. There may be other ways in which instructional practices can be designed and implemented to support teachers in noticing and reflecting during their work.
How do teachers with no computing background learn from their instructional experiences? Ms. Robinson, Mr. Miller, and Mr. Perez all had prior experience with computer science. In the case of Ms. Robinson and Mr. Miller, this experience dated back several years but it still provided them with familiarity of their course content. Teachers completely new to CS might learn from their instructional practices in different ways than teachers who enter classrooms with some content knowledge.

How do other models of co-teaching support teacher learning? The distribution of instructional responsibilities between teachers and volunteers was influential in providing teachers with learning opportunities. However, the PL program encouraged "one teach, one assist" and "team teaming" [44] models of co-teaching, so we were not able to explore the utility of other co-teaching models. Do other models, such as parallel teaching where each instructor teaches the same material to different groups of students in the same classroom, support PCK development differently? Also, the PL program we studied recruited volunteers from the tech industry. While volunteers brought CS content knowledge to their teaching team, not all volunteers had pedagogical knowledge or experience. Would the supports provided through the co-teaching model differ if volunteers also had computing PCK?

\section{ACKNOWLEDGMENTS}

This material is based upon work supported by the National Science Foundation under Grant No.: 1348866. Any opinions, findings, and conclusions or recommendations expressed in this material are those of the authors and do not necessarily reflect the view of the National Science Foundation.

We would like to thank Angela Knotts and Joseph Green for their invaluable support in data collection. We are also grateful to Dr. Yvonne Kao and Dr. Steven Schneider for securing the funding to support this project and for Dr. Kao's feedback on earlier drafts of this paper.

\section{REFERENCES}

[1] Robert K. Atkinson, Sharon J. Derry, Alexander Renkl, and Donald Wortham. 2000. Learning from Examples: Instructional Principles from the Worked Examples Research. Review of Educational Research 70, 2 (June 2000), 181-214. https: //doi.org/10.3102/00346543070002181

[2] Beatrice Avalos. 2011. Teacher Professional Development in Teaching and Teacher Education over ten years. Teaching and Teacher Education: An International Journal of Research and Studies 27, 1 (Jan. 2011), 10-20. https://doi.org/10.1016/j. tate.2010.08.007

[3] Deborah Loewenberg Ball and D Cohen. 1999. Developing Practice, Developing Practitioners: Toward a practice-based theory of professional education. Teaching as the Learning Profession San Francisco: fossey-Bass (1999).

[4] Deborah Loewenberg Ball and Francesca M. Forzani. 2009. The Work of Teaching and the Challenge for Teacher Education. Fournal of Teacher Education 60, 5 (Nov. 2009), 497-511. https://doi.org/10.1177/0022487109348479

[5] Deborah Loewenberg Ball, Mark Hoover Thames, and Geoffrey Phelps. 2008. Content Knowledge for Teaching What Makes It Special? Journal of Teacher Education 59, 5 (Nov. 2008), 389-407. https://doi.org/10.1177/0022487108324554

[6] Juliet A. Baxter. 1987. Teacher Explanations in Computer Programming: A Study of Knowledge Transformation. Doctoral Dissertation. Stanford University, CA, United States.

[7] David C. Berliner. 2004. Describing the Behavior and Documenting the Accomplishments of Expert Teachers. Bulletin of Science, Technology \& Society 24, 3 (June 2004), 200-212. https://doi.org/10.1177/0270467604265535

[8] Sigrid BlÃümeke and SeÃąn Delaney. 2012. Assessment of teacher knowledge across countries: a review of the state of research. ZDM Mathematics Education 44, 3 (July 2012), 223-247. http://search.ebscohost.com/login.aspx?direct=true\&

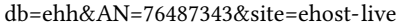


[9] Hilda Borko. 2004. Professional Development and Teacher Learning: Mapping the Terrain. Educational Researcher 33, 8 (Nov. 2004), 3-15. https://doi.org/10. 3102/0013189X033008003 http://media.leidenuniv.nl/legacy/educ-researcher-33(2004)-3-15-borko-professional-development-and-teacher-learning.pdf.

[10] Malte Buchholz, Mara Saeli, and Carsten Schulte. 2013. PCK and Reflection in Computer Science Teacher Education. In Proceedings of the 8th Workshop in Primary and Secondary Computing Education (WiPSE '13). ACM, New York, NY, USA, 8-16. https://doi.org/10.1145/2532748.2532752

[11] John L. Campbell, Charles Quincy, Jordan Osserman, and Ove K. Pedersen. 2013 Coding In-depth Semistructured Interviews Problems of Unitization and Intercoder Reliability and Agreement. Sociological Methods \& Research (Aug. 2013), 0049124113500475. https://doi.org/10.1177/0049124113500475

[12] Jan Cuny. 2015. Transforming K-12 Computing Education: AP\&Reg; Computer Science Principles. ACM Inroads 6, 4 (Nov. 2015), 58-59. https://doi.org/10.1145/ 2832916

[13] Linda Darling-Hammond. 2008. Teacher learning that supports student learning. Teaching for intelligence 2, 1 (2008), 91-100.

[14] Fien Depaepe, Lieven Verschaffel, and Geert Kelchtermans. 2013. Pedagogical content knowledge: A systematic review of the way in which the concept has pervaded mathematics educational research. Teaching and Teacher Education 34 (Aug. 2013), 12-25. https://doi.org/10.1016/j.tate.2013.03.001

[15] Barbara Ericson, M. Armoni, J. Gal-Ezer, D. Seehorn, C. Stephenson, and F. Trees. 2008. Ensuring exemplary teaching in an essential discipline: Addressing the crisis in computer science teacher certification. Technical Report. The Computer Science Teachers Association, New York.

[16] Sharon Feiman-Nemser. 2003. What New Teachers Need To Learn. Educational Leadership 60, 8 (Jan. 2003), 25-29.

[17] David F. Feldon. 2007. Cognitive Load and Classroom Teaching: The DoubleEdged Sword of Automaticity. Educational Psychologist 42, 3 (2007), 123-137. https://doi.org/10.1080/00461520701416173

[18] Francesca M. Forzani. 2014. Understanding âĂIJCore PracticesâĂİ and âĂIJPractice-BasedâĂİ Teacher Education: Learning From the Past. fournal of Teacher Education 65, 4 (Sept. 2014), 357-368. https://doi.org/10.1177/ 0022487114533800

[19] Michael S. Garet, Andrew C. Porter, Laura Desimone, Beatrice F. Birman, and Kwang Suk Yoon. 2001. What Makes Professional Development Effective? Results From a National Sample of Teachers. American Educational Research fournal 38, 4 (Dec. 2001), 915-945. https://doi.org/10.3102/00028312038004915

[20] Lynn T. Goldsmith, Helen M. Doerr, and Catherine C. Lewis. 2014. Mathematics teachersâĂŹ learning: a conceptual framework and synthesis of research. fournal of Mathematics Teacher Education 17, 1 (Feb. 2014), 5-36. https://doi.org/10.1007/ s10857-013-9245-4

[21] Jean Griffin, Tammy Pirmann, and Brent Gray. 2016. Two Teachers, Two Perspectives on CS Principles. In Proceedings of the 47th ACM Technical Symposium on Computing Science Education (SIGCSE '16). ACM, New York, NY, USA, 461-466. https://doi.org/10.1145/2839509.2844630

[22] Terry Grobe, Susan Curnan, and Alan Melchior. 1990. Synthesis of Existing Knowledge and Practice in the Field of Educational Partnerships. (Dec. 1990).

[23] The White House. 2016. FACT SHEET: President Obama Announces Computer Science For All Initiative [Press Release]. https://www.whitehouse.gov/the-press-office/2016/01/30/ fact-sheet-president-obama-announces-computer-science-all-initiative- 0

[24] Aleata Hubbard, Yvonne Kao, and Danielle Brown. 2016. Designing ThinkAloud Interviews to Elicit Evidence of Computer Science Pedagogical Content Knowledge. Washington, D.C.

[25] Peter Hubwieser, Michail N. Giannakos, Marc Berges, Torsten Brinda, Ira Diethelm, Johannes Magenheim, Yogendra Pal, Jana Jackova, and Egle Jasute. 2015 A Global Snapshot of Computer Science Education in K-12 Schools. In Proceedings of the 2015 ITiCSE on Working Group Reports (ITICSE-WGR '15). ACM, New York, NY, USA, 65-83. https://doi.org/10.1145/2858796.2858799

[26] Elham Kazemi, Magdalene Lampert, and Hala Ghousseini. 2007. Conceptualizing and Using Routines of Practice in Mathematics Teaching to Advance Professional Education / Spencer. Technical Report. Spencer Foundation, Chicago, IL. http://www.spencer.org/conceptualizing-and-using-routines-practicemathematics-teaching-advance-professional-education

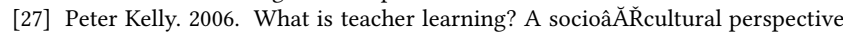
Oxford Review of Education 32, 4 (Sept. 2006), 505-519. https://doi.org/10.1080/ 03054980600884227

[28] Klaus Krippendorff. 2011. Computing Krippendorff's Alpha-Reliability. Departmental Papers (ASC) (Jan. 2011). http://repository.upenn.edu/asc_papers/43

[29] Klaus Krippendorff. 2012. Content Analysis: An Introduction to Its Methodology. SAGE. Google-Books-ID: s_yqFXnGgjQC.

[30] Karen Lang, Ria Galanos, Joanna Goode, Deborah Seehorn, and Fran Trees 2013. Bugs in the System: Computer Science Teacher Certification in the U.S. Technical Report. Computer Science Teachers Association. http://csta.acm.org/ ComputerScienceTeacherCertification/sub/CSTA_BugsInTheSystem.pdf
[31] Tami Lapidot. 2005. Computer Science Teachers' Learning during their Everyday Work. Doctoral Dissertation. Technion University, Israel.

[32] Neomi Liberman, Yifat Ben-David Kolikant, and Catriel Beeri. 2012. "Regressed Experts" as a New State in Teachers' Professional Development: Lessons from Computer Science Teachers' Adjustments to Substantial Changes in the Curriculum. Computer Science Education 22, 3 (Jan. 2012), 257-283. http://search.ebscohost.com/login.aspx?direct=true \&db=eric\&AN= EJ980739\&site $=$ ehost-live

[33] John Loughran, Pamela Mulhall, and Amanda Berry. 2004. In search of pedagogical content knowledge in science: Developing ways of articulating and documenting professional practice. Journal of Research in Science Teaching 41, 4 (April 2004), 370-391. https://doi.org/10.1002/tea.20007

[34] Morva McDonald, Elham Kazemi, and Sarah Schneider Kavanagh. 2013. Core Practices and Pedagogies of Teacher Education: A Call for a Common Language and Collective Activity. Journal of Teacher Education 64, 5 (Nov. 2013), 378-386. https://doi.org/10.1177/0022487113493807

[35] Muhsin Menekse. 2015. Computer science teacher professional development in the United States: a review of studies published between 2004 and 2014. Computer Science Education 25, 4 (Dec. 2015), 325-350. http://search.ebscohost.com/login. aspx?direct=true \&db=ehh\&AN=114015739\&site=ehost-live

[36] Briana B. Morrison, Lauren E. Margulieux, Barbara Ericson, and Mark Guzdial. 2016. Subgoals Help Students Solve Parsons Problems. In Proceedings of the 47th ACM Technical Symposium on Computing Science Education (SIGCSE '16). ACM, New York, NY, USA, 42-47. https://doi.org/10.1145/2839509.2844617

[37] Lijun Ni and Mark Guzdial. 2012. Who AM I?: Understanding High School Computer Science Teachers' Professional Identity. In Proceedings of the 43rd ACM Technical Symposium on Computer Science Education (SIGCSE '12). ACM, New York, NY, USA, 499-504. https://doi.org/10.1145/2157136.2157283

[38] Margaret Niess, Gogot Suharwoto, K Lee, and Pejmon Sadri. 2006. Guiding inservice mathematics teachers in developing technology pedagogical content knowledge (TPCK). In Society for Information Technology and Teacher Education Annual Conference. 20-24.

[39] The City of New York 2016. Equity and Excellence: Mayor de Blasio Announces Reforms to Raise Achievement Across all Public Schools [Press Release]. http://www1.nyc.gov/office-of-the-mayor/news/618-15/ equity-excellence-mayor-de-blasio-reforms-raise-achievement-across-all-public

[40] V. Darleen Opfer and David Pedder. 2011. Conceptualizing Teacher Professional Learning. Review of Educational Research 81, 3 (Sept. 2011), 376-407. http://search.ebscohost.com/login.aspx?direct=true \&db=eric\&AN= EJ936871\&site $=$ ehost-live

[41] Justus J. Randolph, G Julnes, E Sutinen, and S Lehman. 2008. A methodological review of computer science education research. Fournal of Information Technology Education 7 (2008), 135-162. file://C:/northwestern/compSci endnote. Data/PDF/randolph methodologicalreviewofcsedresearch-2730054661/ randolph_methodologicalreviewofcsedresearch.pdfinternal-pdf:// randolphDissertation-0150228741/randolphDissertation.pdf

[42] Rebecca M. Schneider and Kellie Plasman. 2011. Science Teacher Learning Progressions: A Review of Science Teachers' Pedagogical Content Knowledge Development. Review of Educational Research (Oct. 2011), 0034654311423382. https://doi.org/10.3102/0034654311423382

[43] Chicago Public Schools. 2014. CPS Announces First Schools to Implement DistrictâĂŹs Comprehensive K-12 Curriculum [Press Release]. http://cps.edu/News/ Press_releases/Pages/PR1_03_19_2014.aspx

[44] Thomas E. Scruggs, Margo A. Mastropieri, and Kimberly A. McDuffie. 2007. Co-Teaching in Inclusive Classrooms: A Metasynthesis of Qualitative Research. Exceptional Children 73, 4 (July 2007), 392-416. https://doi.org/10.1177/ 001440290707300401

[45] Lee Shulman. 1986. Those who understand: Knowledge growth in teaching. Educational Researcher 15 (1986), 4-14. 2.

[46] I.R. Weiss, J.D. Pasley, P.S. Smith, E.R. Banilower, and D.J. Heck. 2003. Looking Inside the Classroom: A Study of K-12 Mathematics and Science Education in the United States. Technical Report.

[47] Suzanne M. Wilson, Jeffrey J. Rozelle, and Jamie N. Mikeska. 2011. Cacophony or Embarrassment of Riches: Building a System of Support for Quality Teaching. fournal of Teacher Education 62, 4 (Sept. 2011), 383-394. http://search.ebscohost. com/login.aspx?direct=true \&db=eric \&AN=EJ940391\&site=ehost-live 